Article

\title{
Inversion of Land Surface Temperature (LST) Using Terra ASTER Data: A Comparison of Three Algorithms
}

\author{
Milton Isaya Ndossi * and Ugur Avdan \\ Institute of Space and Earth Sciences, Anadolu University, Iki Eylul Campus, Eskisehir 26555, Turkey; \\ uavdan@anadolu.edu.tr \\ * Correspondence: milton_issaya@hotmail.com; Tel.: +90-539-462-15-53 \\ Academic Editors: George P. Petropoulos, Zhaoliang Li and Prasad S. Thenkabail \\ Received: 9 September 2016; Accepted: 23 November 2016; Published: 2 December 2016
}

\begin{abstract}
Land Surface Temperature (LST) is an important measurement in studies related to the Earth surface's processes. The Advanced Space-borne Thermal Emission and Reflection Radiometer (ASTER) instrument onboard the Terra spacecraft is the currently available Thermal Infrared (TIR) imaging sensor with the highest spatial resolution. This study involves the comparison of LSTs inverted from the sensor using the Split Window Algorithm (SWA), the Single Channel Algorithm (SCA) and the Planck function. This study has used the National Oceanic and Atmospheric Administration's (NOAA) data to model and compare the results from the three algorithms. The data from the sensor have been processed by the Python programming language in a free and open source software package (QGIS) to enable users to make use of the algorithms. The study revealed that the three algorithms are suitable for LST inversion, whereby the Planck function showed the highest level of accuracy, the SWA had moderate level of accuracy and the SCA had the least accuracy. The algorithms produced results with Root Mean Square Errors (RMSE) of $2.29 \mathrm{~K}, 3.77 \mathrm{~K}$ and $2.88 \mathrm{~K}$ for the Planck function, the SCA and SWA respectively.
\end{abstract}

Keywords: land surface temperature (LST); split window algorithm (SWA); single channel algorithm (SCA); thermal infrared (TIR); Planck function; python

\section{Introduction}

Land Surface Temperature (LST) is the temperature of the surface of the Earth. LST is among the most important datasets collected by satellites from space. LST is used in many applications such as evapotranspiration, hydrology, climate change, geothermal energy related studies, Earth heat budget studies and many others [1-3]. LST varies rapidly with time and location [4], and, as a result, in order be able to acquire accurate LST measurements over time, there arises a need to estimate LST in a relatively higher spatial resolution. Due to the high variation of temperature over land, satellite derived LST provides researchers with a unique opportunity to acquire LST of the entire globe with a relatively high spatial resolution in average values rather than values in a point form [5]. Through LST derived from space, users of satellite imagery are now able to collect data, even from remote and inaccessible regions such as the poles and oceans.

On board the Terra satellite, The Advanced Space-borne Thermal Emission and Reflection Radiometer (ASTER) instrument is equipped with Thermal Infrared (TIR) sensors that can detect long-wave thermal infrared radiation with wavelengths between 8 and $12 \mu \mathrm{m}$. On 1 April 2016, the National Aeronautics and Space Administration (NASA) and the Japanese Space Agency announced that ASTER data will be provided free of charge. This provides more researchers with an opportunity to study the Earth in a different perspective. Until then, ASTER had a total of more than 2.95 million 
individual scenes which cover almost $99 \%$ of the Earth [6]. Because of the free availability of ASTER data, it is expected that more users will make use of the data collected by the instrument.

Several algorithms have been developed to enable the extraction of LST from Visible, Near Infrared (VNIR) and TIR imagery acquired from the ASTER sensor [7-9]. These algorithms can be categorized in two main groups: algorithms based on one thermal channel (single channel algorithms) and algorithms based on more than one TIR channel (split window algorithms). This study has mainly focused on the examination of the algorithms which are used to derive LST from the ASTER instrument with the use of Land Surface Emissivities (LSEs) derived from the VNIR channels and the TIR channels onboard the ASTER instrument. Despite the presence of these algorithms today, their implementation in LST inversion is not an easy process. Due to the difficulties arising from the implementation of these algorithms in software already available in the market and the cost of acquisition of Remote Sensing (RS) and Geographic Information Systems (GIS) software, most users have not managed to make use of these algorithms. The availability of a ready-made solution for LST extraction not only promotes the use of these algorithms but also enables users from other fields to make use of the data obtained from the sensor.

This study involves the implementation of the Split Window Algorithm (SWA) [10], the Single Channel Algorithm (SCA) for ASTER [7] and the Planck function [11] in the form of a Python-Quantum GIS (PyQGIS) plugin in a free and open source software known as QGIS/Quantum GIS [12] to estimate land surface temperature from ASTER Visible, Near Infrared (VNIR) and TIR imagery. In addition to that, the plugin can also be used to calculate radiance, land surface emissivity and brightness temperature. The geoprocessing code used in this study has been provided as an update to a plugin which was developed for Landsat sensors [13]. It is free to modify, view and share, enabling more users to benefit from it.

NOAA Surface Radiation (SURFRAD) [14] data have been used in the accuracy assessment and modeling of the results obtained from the sensor. To develop the plugin, the Python programming language has been used because it can run on the most used operating systems, i.e., Linux, Windows and Mac OS, without the modification or recompilation of the code; Python is a free and open source programming language; and because the language has the ability to create Graphical User Interface (GUI) and, which eases the use of the plugin.

\section{Data and Materials}

\subsection{ASTER Imagery}

The ASTER instrument's scene consists of fourteen channels which can detect electromagnetic radiation ranging from the visible region to the thermal infrared region of the electromagnetic spectrum. The sensor was launched in 1999 and it is one of the instruments carried by National Aeronautics and Space Administration's (NASA) Terra spacecraft. Table 1 shows the technical specifications of the ASTER sensor. The ASTER data used in this study were acquired from the United States Geological Survey (USGS) Earth-Explorer website [15]. In this study, a total of 16 ASTER level 1T radiance at sensor imagery have been used. These scenes were collected in different periods of time, from different latitudes, land covers and topography. Table 2 shows the scenes that have been used in the study. 
Table 1. ASTER instrument's technical specifications.

\begin{tabular}{|c|c|c|c|c|}
\hline Subsystem & Band & Spectral Range $(\mu \mathrm{m})$ & Spatial Resolution & Quantization \\
\hline \multirow{4}{*}{$\begin{array}{l}\text { Visible and Near } \\
\text { Infrared (VNIR) }\end{array}$} & 1 & $0.52-0.60$ & \multirow{4}{*}{$15 \mathrm{~m}$} & \multirow{4}{*}{8 bits } \\
\hline & 2 & $0.63-0.69$ & & \\
\hline & $3 \mathrm{~N}$ & $0.78-0.76$ & & \\
\hline & $3 \mathrm{~B}$ & $0.78-0.76$ & & \\
\hline \multirow{6}{*}{$\begin{array}{c}\text { Short Wave } \\
\text { Infrared (SWIR) }\end{array}$} & 4 & $1.60-1.70$ & \multirow{6}{*}{$30 \mathrm{~m}$} & \multirow{6}{*}{8 bits } \\
\hline & 5 & $2.145-2.185$ & & \\
\hline & 6 & $2.185-2.225$ & & \\
\hline & 7 & $2.235-2.285$ & & \\
\hline & 8 & $2.295-2.365$ & & \\
\hline & 9 & $2.360-2.430$ & & \\
\hline \multirow{5}{*}{$\begin{array}{l}\text { Thermal Infrared } \\
\text { (TIR) }\end{array}$} & 10 & $8.125-8.475$ & \multirow{5}{*}{$90 \mathrm{~m}$} & \multirow{5}{*}{12 bits } \\
\hline & 11 & $8.475-8.825$ & & \\
\hline & 12 & $8.925-9.275$ & & \\
\hline & 13 & $10.25-10.95$ & & \\
\hline & 14 & $10.95-11.65$ & & \\
\hline
\end{tabular}

Table 2. ASTER scenes used in the study.

\begin{tabular}{ccccc}
\hline Scene Acquisition Date & Scene Acquisition Time (UTC) & Path & Row & Scene ID \\
\hline 10 October 2000 & $17: 07$ & 22 & 32 & 4 \\
10 October 2000 & $17: 08$ & 23 & 36 & 13 \\
11 June 2001 & $18: 13$ & 35 & 26 & 7 \\
30 August 2001 & $18: 11$ & 35 & 26 & 9 \\
7 November 2001 & $16: 51$ & 23 & 32 & 2 \\
27 February 2002 & $16: 50$ & 23 & 36 & 12 \\
6 March 2003 & $16: 54$ & 23 & 32 & 1 \\
31 December 2003 & $16: 49$ & 23 & 36 & 14 \\
11 March 2004 & $16: 55$ & 22 & 36 & 10 \\
19 September 2004 & $16: 52$ & 23 & 32 & 5 \\
30 October 2004 & $16: 45$ & 23 & 32 & 6 \\
14 June 2006 & $16: 48$ & 22 & 36 & 11 \\
1 August 2006 & $16: 46$ & 23 & 32 & 3 \\
14 October 2006 & $17: 22$ & 29 & 30 & 16 \\
9 January 2007 & $14: 29$ & 29 & 30 & 15 \\
18 April 2008 & $18: 11$ & 35 & 26 & 8 \\
\hline
\end{tabular}

\subsection{Surface Radiation Budget Network (SURFRAD) Data}

This study employed data obtained from the National Oceanic and Atmospheric Administration's (NOAA) Surface Radiation budget network (SURFRAD). The network was established in 1995 with four stations, which were later expanded to six in 1998. The purpose of the SURFRAD network is to provide correct, continuous and accurate measurements related to radiation budget for use in climatology, satellite related studies, weather forecasting and education. The choice of the locations of the establishment of SURFAD stations involved experts from NOAA, universities and NASA. The network has given special attention to satellite data validation as the stations are located in areas with a continuous span of homogeneous landforms and vegetation cover in order for the stations to be able to make measurements with a correct representation of the spatial resolution of a satellite's pixel [14]. This study has made use of SURFRAD data, as they have been used successfully in numerous studies related to LST inversion from space [16-18]. Table 3 shows the information of the stations. The scenes used in the study and the SURFRAD stations they cover are also shown on Table 3. The scenes can be identified using the scene IDs shown from the table. 
Table 3. SURFRAD Stations Information [19].

\begin{tabular}{cccccccc}
\hline $\begin{array}{c}\text { Station } \\
\text { Name }\end{array}$ & $\begin{array}{c}\text { Latitude, } \\
\text { Longitude }\end{array}$ & Land Cover & $\begin{array}{c}\text { Elevation } \\
\text { (Meters) }\end{array}$ & $\begin{array}{c}\text { U.S. } \\
\text { State }\end{array}$ & $\begin{array}{c}\text { Date of } \\
\text { Installation }\end{array}$ & $\begin{array}{c}\text { Station } \\
\text { Code }\end{array}$ & $\begin{array}{c}\text { Scene } \\
\text { ID }\end{array}$ \\
\hline Bondville & $\begin{array}{c}40.06^{\circ} \mathrm{N}, \\
88.37^{\circ} \mathrm{W}\end{array}$ & Cropland & 230 & IL & January 1995 & BON & $\begin{array}{c}1,2,3,4, \\
5,6\end{array}$ \\
\hline Fort Peck & $\begin{array}{r}48.31^{\circ} \mathrm{N}, \\
105.10^{\circ} \mathrm{W}\end{array}$ & Grassland & 634 & MT & January 1995 & FPK & $7,8,9$ \\
\hline $\begin{array}{c}\text { Goodwin } \\
\text { Creek }\end{array}$ & $\begin{array}{c}34.25^{\circ} \mathrm{N}, \\
89.87^{\circ} \mathrm{W}\end{array}$ & $\begin{array}{c}\text { Evergreen Needle } \\
\text { Leaf Forest }\end{array}$ & 98 & MS & January 1995 & GWN & $\begin{array}{r}10,11,1 \\
12,13\end{array}$ \\
\hline Sioux Falls & $\begin{array}{l}43.73^{\circ} \mathrm{N}, \\
96.62^{\circ} \mathrm{W}\end{array}$ & Cropland & 473 & SD & June 2003 & SXFs & 15,16 \\
\hline
\end{tabular}

\section{Methodology}

\subsection{Conversion of Digital Numbers (DNs) to Radiance}

Radiance at the sensor data is stored in ASTER thermal infrared imagery in the form of DNs. DNs are the values stored in raw satellite imagery which have not yet been processed. DNs are a way to represent different levels of intensities of electromagnetic radiation in a raster image [20]. To calculate LST from this imagery, DNs should be converted to radiance. To convert DNs to radiance, Equation (1) has been used in the study [20].

$$
\mathrm{L}_{\lambda}=(\mathrm{DN}-1) \times \mathrm{UCC},
$$

where $\mathrm{L}_{\lambda}$ represents the top of atmosphere radiance in $\mathrm{W} /\left(\mathrm{m}^{2} \cdot \mathrm{sr} \cdot \mu \mathrm{m}\right), \mathrm{DN}$ represents the ASTER thermal infrared band being used in the study and UCC stands for the Unit Conversion Coefficient of the thermal infrared band in use. Table 4 shows the UCCs of the thermal bands of the ASTER instrument [21].

Table 4. Unit Conversion Coefficients (UCC) of ASTER's TIR bands [21].

\begin{tabular}{cccccc}
\hline Band & Band 10 & Band 11 & Band 12 & Band 13 & Band 14 \\
\hline UCC & 0.006822 & 0.006780 & 0.006590 & 0.005693 & 0.005225 \\
\hline
\end{tabular}

\subsection{Conversion of Radiance to Brightness Temperature}

Brightness temperature is a measurement that describes the amount of radiation in terms of the temperature of a hypothetical blackbody emitting the same amount of radiation at the same wavelength [22]. The application of the inverse of the Planck function to the measured radiation calculates the brightness temperature. Brightness temperature may be highly dependent or independent on the wavelength of the radiation depending on the properties of the source of radiation and any subsequent absorption [22]. After the DNs have been converted to radiance, the next step is to convert the radiance to brightness temperature (Equation (2)) [7,21,23]:

$$
\mathrm{T}_{\mathrm{sen}}=\frac{\mathrm{K}_{2}}{\ln \left(\frac{\mathrm{K}_{1}}{\mathrm{~L}_{\lambda}}+1\right)}
$$

where $T_{\text {sen }}$ represents the top of atmosphere brightness temperature in Kelvin, $L_{\lambda}$ represents the top of atmosphere radiance from Equation (1), $K_{1}$ and $K_{2}$ are the band specific thermal conversion constants which are based on the wavelength of the operation of a thermal infrared channel. $K_{1}=C_{1} / \lambda^{5}$ and $\mathrm{K}_{2}=\mathrm{C}_{2} / \lambda$. Table 5 shows the $\mathrm{K}_{1}, \mathrm{~K}_{2}$ coefficients of the TIR bands of the ASTER instrument. 
Table 5. $K_{1}$ and $K_{2}$ coefficients of the TIR bands of the ASTER instrument [7].

\begin{tabular}{ccc}
\hline Band & $\mathbf{K}_{\mathbf{1}} \mathbf{( W \cdot \mathbf { m } ^ { \mathbf { 2 } } \cdot \mathbf { s r }} \mathbf{- 1}^{\mathbf{1}} \boldsymbol{\mu \mathbf { m } ^ { - \mathbf { 1 } } )}$ & $\left.\mathbf{K}_{\mathbf{2}} \mathbf{( W \cdot \mathbf { m } ^ { \mathbf { 2 } } \cdot \mathbf { s r }} \mathbf{- 1}^{\mathbf{1}} \boldsymbol{\mu} \mathbf{m}^{\mathbf{- 1}}\right)$ \\
\hline Band 10 & 3047.47 & 1736.18 \\
Band 11 & 2480.93 & 1666.21 \\
Band 12 & 1930.80 & 1584.72 \\
Band 13 & 865.65 & 1349.82 \\
Band 14 & 649.60 & 1274.49 \\
\hline
\end{tabular}

\subsection{Estimation of Land Surface Emissivity (LSE)}

Emissivity is the ratio of the power emitted by a body at a known temperature to the power emitted if the body obeyed Planck's law of radiation [24]. The emissivities of most terrestrial materials lies between 0.7 and 1 [1], however, surfaces that have emissivities less than 0.85 are likely to be found in deserts [1,25]. It is important to estimate LSE, as it reduces the errors during the estimation of LST from space [26]. Unlike the emissivity of water bodies such as oceans, the emissivity of land surfaces may significantly differ from one place to another [16]. Emissivity may differ according to the viewing angle, surface moisture, and roughness as well as with vegetation [16,27]. Notwithstanding the fact that there are many algorithms that have been proposed for the estimation of LSE [28-31], in this study, the estimation of LSE with prior known LSE has been used. This is because the algorithm is more practical and has a reasonable accuracy $[16,32,33]$. Previous studies have proven the presence of a relationship between the Normalized Difference Vegetation Index (NDVI) and the emissivities of terrestrial materials [9,34]. In this study, the NDVI based approach of LSE estimation has been used [9,35]. This algorithm has been applied in the estimation of LSE for various sensors [32,36-39] with the use of Visible and Near Infrared (VNIR) data. To calculate the NDVI, Equation (3) has been used in the study [40].

$$
\mathrm{NDVI}=\frac{\mathrm{NIR}-\mathrm{RED}}{\mathrm{NIR}+\mathrm{RED}}
$$

where NIR represents the reflectance of the Near Infrared band and RED represents the reflectance of red band of the ASTER sensor.

In this study, Jimenez-Munoz and coworkers' algorithm [9] has been used in the estimation of LSE from NDVI. This algorithm has been used as it has been tested with in situ data for ASTER. The algorithm is based on Equation (4) [9].

$$
\varepsilon_{\mathrm{i}}=\varepsilon_{\mathrm{vi}} \mathrm{P}_{\mathrm{v}}+\varepsilon_{\mathrm{si}}\left(1-\mathrm{P}_{\mathrm{v}}\right)
$$

where $\varepsilon_{\mathrm{i}}$ represents the emissivity of thermal infrared channel $\mathrm{i} ; \varepsilon_{\mathrm{vi}}$ and $\varepsilon_{\mathrm{si}}$ represent the channel emissivities of vegetation and soil, respectively; and $\mathrm{P}_{\mathrm{V}}$ represents the proportion of vegetation (sometimes known as fractional vegetation cover). A cavity term is added to Equation (4) to take the geometric distribution of the surface into consideration during the LSE estimation. The cavity effect for an area with a mixed land cover in a near nadir angle is given by $\left(1-\varepsilon_{\mathrm{S}}\right) \varepsilon_{\mathrm{V}} \mathrm{F}^{\prime}\left(1-\mathrm{P}_{\mathrm{V}}\right)$, where $\mathrm{F}^{\prime}$ is a geometric value which ranges between 0 and 1 [9]. The cavity term has been neglected because of its small effect in the estimation of LSE in areas with high soil emissivities. The proportion of vegetation is calculated from NDVI as shown in Equation (5) [41].

$$
P_{\mathrm{V}}=\left[\frac{\mathrm{NDVI}-\mathrm{NDVI}_{\mathrm{s}}}{\mathrm{NDVI}_{\mathrm{V}}-\mathrm{NDVI}_{\mathrm{s}}}\right]^{2}
$$

where $\mathrm{NDVI}_{\mathrm{V}}$ and $\mathrm{NDVI}_{\mathrm{S}}$ are the NDVI values of vegetation and soil, respectively. These values are obtained from the histogram of the NDVI. According to Jimenez-Munoz et al. [9], the most sensitive issue in Equation (4) is the choice of the emissivity of soil. In order to get the values to apply on Equation (4), authors in [9] introduced Equations (6)-(10) for ASTER TIR band 10 to 14, respectively. 


$$
\begin{aligned}
& \varepsilon_{10}=0.946+0.044 \mathrm{P}_{\mathrm{v}}, \\
& \varepsilon_{11}=0.949+0.041 \mathrm{P}_{\mathrm{v}}, \\
& \varepsilon_{12}=0.941+0.049 \mathrm{P}_{\mathrm{v}}, \\
& \varepsilon_{13}=0.968+0.022 \mathrm{P}_{\mathrm{v}}, \\
& \varepsilon_{14}=0.970+0.020 \mathrm{P}_{\mathrm{v}} .
\end{aligned}
$$

\subsection{Brightness Temperature Emissivity/Atmospheric Correction}

To achieve accurate land surface temperature inversion from space, there arises a need to correct brightness temperatures with emissivity and other atmospheric parameters. Many algorithms have been designed to enable accurate inversion of temperatures from the ASTER instrument's VNIR and TIR channels. This study has employed the Split Window Algorithm (SWA), the Single Channel Algorithm (SCA) for ASTER and the Planck function.

\subsubsection{Single Channel Algorithm for ASTER}

Jiménez-Muñoz and Sobrino adopted the single channel algorithm for the extraction of LST from the ASTER sensor [7]. As a result of the presence of high atmospheric transmission and the lower emissivity variations in the 10-12 $\mu \mathrm{m}$ spectral window as compared to the 8-9 $\mu \mathrm{m}$ spectral window, it was proposed that band 13 and band 14 were the most suitable channels to be used in the algorithm [7]. The algorithm is shown in Equation (11).

$$
\mathrm{T}_{\mathrm{s}}=\gamma\left[\frac{1}{\varepsilon}\left(\Psi \mathrm{L}_{\mathrm{sen}}+\Psi_{2}\right)+\Psi_{3}\right]+\delta
$$

In Equation (11), $\varepsilon$ represents the LSE of an area, $\mathrm{L}_{\mathrm{sen}}$ is the at-sensor radiance $\mathrm{W} /\left(\mathrm{m}^{2} \cdot \mathrm{sr} \cdot \mu \mathrm{m}\right)$, $\gamma$ and $\delta$ are variables which are based on the Planck function and $\Psi_{1}, \Psi_{2}$ and $\Psi_{3}$ are referred to as Atmospheric Functions (AFs) which are estimated using Equations (12)-(14), respectively [7].

$$
\begin{gathered}
\Psi_{1}=\frac{1}{\tau} \\
\Psi_{2}=-\mathrm{L}^{\downarrow}-\frac{\mathrm{L}^{\uparrow}}{\tau} \\
\Psi_{3}=\mathrm{L}^{\downarrow}
\end{gathered}
$$

where $\tau$ is the atmospheric transmittance, $\mathrm{L}^{\uparrow}$ is the upwelling radiance and $\mathrm{L}^{\downarrow}$ is the down-welling atmospheric radiance in the spectral window of the thermal infrared channel in use. In this study, the empirical approach obtained from the second order polynomial fits against the atmospheric water vapor content has been used to determine the AFs (Equation (15)) [42,43]:

$$
\left[\begin{array}{l}
\Psi_{1} \\
\Psi_{2} \\
\Psi_{3}
\end{array}\right]=\left[\begin{array}{lll}
C_{11} & C_{12} & C_{13} \\
C_{21} & C_{22} & C_{23} \\
C_{31} & C_{32} & C_{33}
\end{array}\right]\left[\begin{array}{c}
\mathrm{w}^{2} \\
\mathrm{w} \\
1
\end{array}\right]
$$

In Equation (15), $C_{\mathrm{ij}}$ are obtained from simulated data that are constructed from atmospheric profiles included in different databases and Moderate Resolution Atmospheric Transmission (MODTRAN4) radiative transfer code, and $\mathrm{W}$ is the atmospheric water vapor content of the thermal infrared channel in use. In this study, both TIGR61 and STD66 databases of the MODTRAN4 code were implemented in the plugin. Through them the number of cases have been reduced and a result 
reducing the amount of time required for simulation but are still applicable for global conditions [7]. Table 6 shows the coefficients for the atmospheric functions in a matrix organization [7].

Table 6. Coefficients of the AFs [7].

\begin{tabular}{|c|c|c|c|c|c|}
\hline $\begin{array}{c}\text { MODTRAN } \\
\text { Atmospheric Database }\end{array}$ & $\begin{array}{l}\text { ASTER TIR } \\
\text { Band }\end{array}$ & $C_{i j}$ & $\mathrm{i}=\mathbf{1}$ & $\mathrm{i}=2$ & $\mathrm{i}=3$ \\
\hline STD66 & 13 & $\begin{array}{l}J=1 \\
J=2 \\
J=3\end{array}$ & $\begin{array}{c}0.06524 \\
-0.55835 \\
-0.00284\end{array}$ & $\begin{array}{c}-0.05878 \\
-0.75881 \\
1.35633\end{array}$ & $\begin{array}{c}1.06576 \\
0.00327 \\
-0.43020\end{array}$ \\
\hline TIGR61 & 13 & $\begin{array}{l}J=1 \\
J=2 \\
J=3\end{array}$ & $\begin{array}{c}0.05327 \\
-0.484444 \\
0.00764\end{array}$ & $\begin{array}{c}-0.03937 \\
-0.74611 \\
1.24532\end{array}$ & $\begin{array}{c}1.05742 \\
-0.03015 \\
-0.39461\end{array}$ \\
\hline STD66 & 14 & $\begin{array}{l}J=1 \\
J=2 \\
J=3\end{array}$ & $\begin{array}{c}0.10062 \\
-0.79740 \\
-0.03091\end{array}$ & $\begin{array}{c}-0.13563 \\
-0.39414 \\
1.60094\end{array}$ & $\begin{array}{c}1.10559 \\
-0.17664 \\
-0.56515\end{array}$ \\
\hline TIGR61 & 14 & $\begin{array}{l}J=1 \\
J=2 \\
J=3\end{array}$ & $\begin{array}{c}0.07965 \\
-0.66528 \\
-0.01578\end{array}$ & $\begin{array}{c}-0.09580 \\
-0.48582 \\
1.46358\end{array}$ & $\begin{array}{c}1.08983 \\
-0.17029 \\
-0.52486\end{array}$ \\
\hline
\end{tabular}

The gamma $(\gamma)$ and delta $(\delta)$ parameters shown in Equation (11) are computed using Equations (16) and (17), respectively [7], where $T_{\text {sen }}$ is obtained from Equation (2) and the values of $K_{2}$ are shown in Table 5.

$$
\begin{gathered}
\gamma \approx \frac{\mathrm{T}_{\mathrm{sen}}^{2}}{\mathrm{~K}_{2} \mathrm{~L}_{\mathrm{sen}}} \\
\delta \approx \mathrm{T}_{\mathrm{sen}}-\frac{\mathrm{T}_{\mathrm{sen}}^{2}}{\mathrm{~K}_{2}}
\end{gathered}
$$

\subsubsection{Split Window Algorithm (SWA)}

The SWA was developed to enabling the extraction of LST from instruments that are equipped with more than one TIR channel. The algorithm was initially introduced for the estimation of Sea Surface Temperature (SST) and was later adopted for the extraction of LST. It takes advantage of the differences in absorption between two thermal infrared channels in the atmospheric window between 10.5 and $12.5 \mu \mathrm{m}$. Many SWA equations have been derived by numerous researchers for LST estimation [44-46]. With an exception of the way these algorithms calculate their parameters, they operate in the same manner [47]. In this study, Mao and coworkers' SWA has been used [8]. The algorithm used is shown in Equation (18). The temperature derived from the equation is measured in Kelvin.

$$
\begin{gathered}
\mathrm{T}_{\mathrm{s}}=\frac{\left\{\left[\mathrm{C}_{14}\left(\mathrm{D}_{13}+\mathrm{B}_{13}\right)\right]-\left[\mathrm{C}_{13}\left(\mathrm{D}_{14}+\mathrm{B}_{14}\right)\right]\right\}}{\mathrm{C}_{14} \mathrm{~A}_{13}-\mathrm{C}_{13} \mathrm{~A}_{14}} \\
\mathrm{~A}_{13}=0.145236 \times \varepsilon_{13} \times \tau_{13} \\
\mathrm{~B}_{13}=0.145236 \times \mathrm{T}_{13}+33.685 \times \varepsilon_{13} \times \tau_{13}-33.685 \\
\mathrm{C}_{13}=\left(1-\tau_{13}\right) \times\left[1+\left(1-\varepsilon_{13}\right) \times \tau_{13}\right] \times 0.145236 \\
\mathrm{D}_{13}=\left(1-\tau_{13}\right) \times\left[1+\left(1-\varepsilon_{13}\right) \times \tau_{13}\right] \times 33.685 \\
\mathrm{~A}_{14}=0.13266 \times \varepsilon_{14} \times \tau_{14} \\
\mathrm{~B}_{14}=0.13266 \times \mathrm{T}_{14}+30.273 \times \varepsilon_{14} \times \tau_{14}-30.273 \\
\mathrm{C}_{14}=\left(1-\tau_{14}\right) \times\left[1+\left(1-\varepsilon_{14}\right) \times \tau_{14}\right] \times 0.13266 \\
\mathrm{D}_{14}=\left(1-\tau_{14}\right) \times\left[1+\left(1-\varepsilon_{14}\right) \times \tau_{14}\right] \times 30.273
\end{gathered}
$$


where $\tau_{13}$ and $\tau_{14}$ stand for the atmospheric transmissions for band 13 and band 14, respectively; $\varepsilon_{13}$ and $\varepsilon_{14}$ stand for the land surface emissivities of band 13 and band 14, respectively; and $\mathrm{T}_{\mathrm{S}}$ represents the land surface temperature.

\subsubsection{Inversion of Planck Function.}

The Planck function is used to compute the intensity of the thermal radiation. It is a function that shows the amount of thermal electromagnetic radiation which can be emitted by a blackbody under thermal equilibrium conditions at a known temperature. With the LSE of an area known, the LST of an area can be estimated through the inversion of the Planck function. The brightness temperature recorded by a sensor in space is calculated under the assumption that the land surface is a black body, i.e., an object with an emissivity of 1 . The Planck function enables the emissivity correction of brightness temperature. The Planck function has been used in the estimation of LST in this study. Emissivity corrected land surface temperature is as shown in Equation (27) [48].

$$
\mathrm{T}_{\mathrm{s}}=\frac{\mathrm{BT}}{\left\{1+\left[\frac{\lambda \cdot \mathrm{BT}}{\rho}\right] \cdot \ln \varepsilon\right\}}
$$

where $T_{S}$ is the land surface temperature in Kelvin, BT represents the brightness temperature of the thermal infrared band in use (obtained from Equation (2)), $\lambda$ is the effective wavelength (in $\mu \mathrm{m}$ ) of the thermal infrared channel in use, $\rho$ is the $(\mathrm{h} \times \mathrm{c} / \sigma)=1.438 \times 10^{-2} \mathrm{~m} \cdot \mathrm{K}$ and $\varepsilon$ is the spectral emissivity. Table 7 shows the effective wavelengths of the TIR channels of the ASTER instrument [7].

Table 7. Effective wavelengths of the TIR channels of the ASTER instrument.

\begin{tabular}{cc}
\hline Band & Effective Wavelength $(\lambda)$ in $\mu \mathrm{m}$ \\
\hline Band 10 & 8.287 \\
Band 11 & 8.685 \\
Band 12 & 9.079 \\
Band 13 & 10.659 \\
Band 14 & 11.289 \\
\hline
\end{tabular}

\subsection{Derival of SURFRAD Land Surface Temperature (LST)}

The LST values used in the study were derived from the radiances recorded by SURFRAD stations. SURFRAD LST can be derived from upwelling wave flux measurements during the satellite overpass time using Equation (28).

$$
\mathrm{F}_{\mathrm{lw}}^{\uparrow}=\varepsilon_{\mathrm{sfc}} \sigma \mathrm{T}_{\mathrm{sfc}}^{4}+\left(1-\varepsilon_{\mathrm{sfc}}\right) \mathrm{F}_{\mathrm{LW}}^{\downarrow}
$$

where $\sigma$ stands for the Stefan-Boltzmann constant $\left(5.670367 \times 10^{-8} \mathrm{~kg} \cdot \mathrm{s}^{-3} \cdot \mathrm{K}^{-4}\right), \mathrm{F}_{\mathrm{lw}}^{\uparrow}$ is the measured upwelling longwave flux, $\mathrm{F}_{\mathrm{LW}}^{\downarrow}$ is the measured down-welling longwave flux and $\varepsilon_{\text {sfc }}$ is the broadband longwave surface emissivity. The broadband longwave surface emissivity is not part of the measurements done by SURFRAD stations. This study has assumed a longwave broadband emissivity of 0.97 . The value represents the findings as stipulated by a study done by Wang and Liang [18] where the broadband values were obtained through the application of a regression analysis using a SeeBor emissivity for the Moderate-Resolution Imaging Spectroradiometer (MODIS) channels with effective wavelengths of $8.5,11$ and $12 \mu \mathrm{m}[17,18]$. This value is only used in the SURFRAD estimate and not in the inversion of LST from the satellite imagery, which includes surface emissivities that vary with time and spatial resolution. In this study, LST of measured by the stations has been solved using Equation (29). Table 8 shows the LSTs derived from the SURFRAD stations used in the study.

$$
\mathrm{LST}=\left\{\frac{\left[\mathrm{F}_{\mathrm{LW}}^{\uparrow}-\left(1-\varepsilon_{\mathrm{sfc}}\right) \mathrm{F}_{\mathrm{LW}}^{\downarrow}\right]}{\left(\varepsilon_{\mathrm{sfc}} \sigma\right)}\right\}^{\frac{1}{4}}
$$


Table 8. LST values derived from the SURFRAD data.

\begin{tabular}{|c|c|c|c|c|c|c|c|}
\hline \multicolumn{2}{|c|}{ Bondville } & \multicolumn{2}{|c|}{ Fort Peck } & \multicolumn{2}{|c|}{ Goodwin Creek } & \multicolumn{2}{|c|}{ Sioux Falls } \\
\hline 6 March 2002 & 286.04 & 11 June 2001 & 302.38 & 11 March 2004 & 296.85 & 9 January 2007 & 271.79 \\
\hline 1 August 2006 & 306.15 & 30 August 2001 & 311.90 & 27 February 2002 & 280.85 & & \\
\hline 10 October 2000 & 290.49 & & & 31 December 2003 & 268.86 & & \\
\hline 19 September 2004 & 296.69 & & & 10 October 2000 & 305.92 & & \\
\hline
\end{tabular}

\subsection{Estimation of Atmospheric Water Vapour}

The atmospheric water vapor used in the study has been estimated from the measurements made by SURFRAD stations using the values of air temperature and relative humidity. Equation (30) shows the relation used in the estimation of atmospheric water vapor content from the SURFRAD data [49].

$$
\mathrm{w}_{\mathrm{i}}=0.0981 \times\left\{10 \times 0.6108 \times \exp \left[\frac{17.27 \times\left(\mathrm{T}_{0}-273.15\right)}{237.3+\left(\mathrm{T}_{0}-273.15\right)}\right] \times \mathrm{RH}\right\}+0.1679
$$

where $\mathrm{w}_{\mathrm{i}}$ represents the atmospheric water vapor content of a thermal infrared channel, $\mathrm{RH}$ represents the relative humidity and $\mathrm{T}_{0}$ represents the near surface air temperature in Kelvin.

\subsection{Estimation of Atmospheric Transmittance $(\tau)$}

To use SWA, the knowledge of the atmospheric transmission of band 13 and band 14 of the ASTER instrument is crucial. In this study, the method proposed by Mao et al. has been used [8]. The inputs required for the successful use of the method have been obtained from the measurements made by the SURFRAD stations. Through the method, the atmospheric transmittance of band 13 and band 14 of the ASTER instrument can be estimated as shown in Equations (31) and (32), respectively.

$$
\begin{aligned}
& \tau_{13}=1.02-0.104 \times \mathrm{w}_{13} \\
& \tau_{14}=1.04-0.113 \times \mathrm{w}_{14}
\end{aligned}
$$

where $w_{13}$ and $w_{14}$ represent the atmospheric water vapor content while $\tau_{13}$ and $\tau_{14}$ represent the band atmospheric transmissions for ASTER band 13 and ASTER band 14, respectively. Figure 1 shows the summary of the methodology used in the study.

\section{Results and Discussion}

This study has only made use of ASTER band 13 and band 14 for LST inversion. Band 10, 11 and 12 have not been used as has been previously recommended that for accurate LST estimation from the sensor. The optimum thermal infrared bands should then be chosen [7]. Accurate LST retrievals are said to be made at the atmospheric windows that lie between 10 and $12 \mu \mathrm{m}$ in wavelength. This is because this window has a higher atmospheric transmittance and lower emissivity uncertainties as compared to the spectral window with wavelengths between 8 and $9 \mu \mathrm{m}$ [7].

The VNIR imagery used in this study were resampled to a spatial resolution of $90 \mathrm{~m}$ and thereafter projected to the Universal Transfer Mercator (UTM) for them to match to the spatial resolution of the ASTER instrument's TIR bands. The imagery used in the study were also clipped to the same extent before being processed. The bias between the LSTs estimated from the ASTER instruments was calculated by subtracting the LST obtained from the SURFRAD station from the LST inverted from the ASTER instrument. 


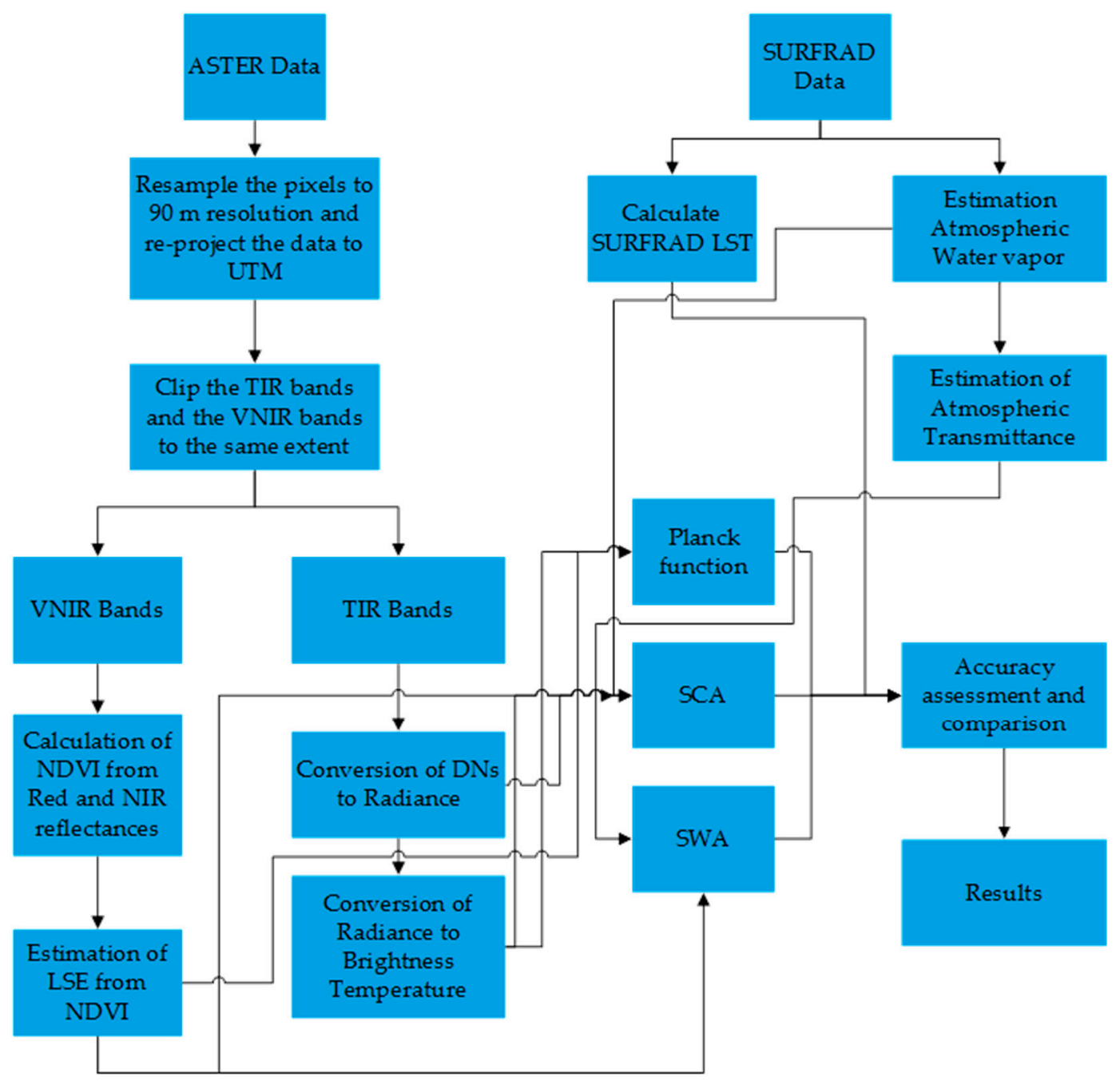

Figure 1. Methodology used in the study.

\subsection{Results from the Planck Function}

The Planck function has been used in this study to derive the LST values from the imagery acquired from the ASTER instrument. The derived values have been compared to the actual land surface temperatures derived from the SURFRAD data. Tables 9 and 10 show a detailed comparison between the different LSTs derived from band 13 and band 14 of the ASTER instrument and the LSTs obtained from SURFRAD stations. All temperatures are measured in Kelvin (K). 
Table 9. Comparison of LST values derived from the SURFRAD stations and the LST inverted by the Planck function using band 13 of the ASTER instrument.

\begin{tabular}{|c|c|c|c|c|c|c|c|c|c|c|c|}
\hline \multicolumn{3}{|c|}{ Bondville } & \multicolumn{3}{|c|}{ Fort Peck } & \multicolumn{3}{|c|}{ Goodwin Creek } & \multicolumn{3}{|c|}{ Sioux Falls } \\
\hline Date & LST (K) & Bias (K) & Date & LST (K) & Bias (K) & Date & LST (K) & Bias (K) & Date & LST (K) & Bias (K) \\
\hline 6 March 2002 & 284.93 & -1.10 & 11 June 2001 & 299.98 & -2.40 & 11 March 2004 & 295.54 & -1.31 & 9 January 2007 & 272.14 & 0.34 \\
\hline 7 November 2001 & 295.50 & 2.89 & 18 April 2008 & 302.52 & 2.26 & 14 June 2006 & 305.08 & -3.54 & 11 October 2006 & 285.39 & -0.57 \\
\hline 1 August 2006 & 302.18 & -3.97 & 30 August 2001 & 311.41 & -0.49 & 27 February 2002 & 279.87 & -0.97 & & & \\
\hline 10 October 2010 & 291.89 & 1.41 & & & & 10 October 2000 & 302.86 & -3.05 & & & \\
\hline 19 September 2004 & 300.61 & 3.92 & & & & & & & & & \\
\hline 30 October 2004 & 290.61 & 0.76 & & & & & & & & & \\
\hline$\Delta$ & & 0.65 & & & -0.21 & & & -2.22 & & & -0.12 \\
\hline$\sigma$ & & 1.66 & & & 1.21 & & & 1.57 & & & 0.32 \\
\hline RMSE & & 2.68 & & & 1.92 & & & 2.48 & & & 0.47 \\
\hline
\end{tabular}

$\Delta:$ Bias, $\sigma:$ Standard Deviation, RMSE: Root Mean Square Error

Table 10. Comparison of LST values derived from the SURFRAD stations and the LST inverted by the Planck function using band 14 of the ASTER instrument.

\begin{tabular}{|c|c|c|c|c|c|c|c|c|c|c|c|}
\hline \multicolumn{3}{|c|}{ Bondville } & \multicolumn{3}{|c|}{ Fort Peck } & \multicolumn{3}{|c|}{ Goodwin Creek } & \multicolumn{3}{|c|}{ Sioux Falls } \\
\hline Date & LST (K) & Bias (K) & Date & LST (K) & Bias (K) & Date & LST (K) & Bias (K) & Date & LST (K) & Bias (K) \\
\hline 6 March 2002 & 284.94 & -1.10 & 11 June 2001 & 299.73 & -2.66 & 11 March 2004 & 295.15 & -1.70 & 9 January 2007 & 272.10 & 0.22 \\
\hline 7 November 2001 & 295.15 & 2.54 & 18 April 2008 & 302.10 & 1.84 & 14 June 2006 & 305.10 & -3.53 & 11 October 2006 & 285.62 & 0.25 \\
\hline 1 August 2006 & 301.16 & -4.99 & 30 August 2001 & 311.02 & -0.88 & 27 February 2002 & 280.06 & -0.79 & & & \\
\hline 10 October 2010 & 292.01 & 1.53 & & & & 10 October 2000 & 305.39 & -0.53 & & & \\
\hline 19 September 2004 & 300.62 & 3.93 & & & & & & -1.64 & & & \\
\hline 30 October 2004 & 290.05 & 0.20 & & & & & & & & & \\
\hline$\Delta$ & & 0.35 & & & -0.56 & & & -1.64 & & & -0.02 \\
\hline$\sigma$ & & 1.66 & & & 1.27 & & & 1.16 & & & 0.23 \\
\hline RMSE & & 2.90 & & & 1.94 & & & 2.02 & & & 0.33 \\
\hline
\end{tabular}

$\Delta$ : Bias, $\sigma:$ Standard Deviation, RMSE: Root Mean Square Error. 
In this study, ASTER band 13 and band 14 produced negative bias values in comparison to the ones derived from SURFRAD data. The average bias values of all scenes used in the study for ASTER band 13 and band 14 were $-0.39 \mathrm{~K}$ and $-0.41 \mathrm{~K}$, respectively. The standard deviation of the LST values obtained from ASTER band 13 and band 14 for all the scenes involved in the study were $1.37 \mathrm{~K}$ and $1.26 \mathrm{~K}$, respectively. There was a high correlation between the LSTs derived from the two bands and the LSTs derived from the SURFRAD data. Both bands produced LST values with regression coefficients $\left(\mathrm{R}^{2}\right)$ of above 0.95 . Figure 2 shows the scatter plots produced to show the relationship between the LSTs derived from ASTER band 13 and 14 from the Planck function with SURFRAD data.

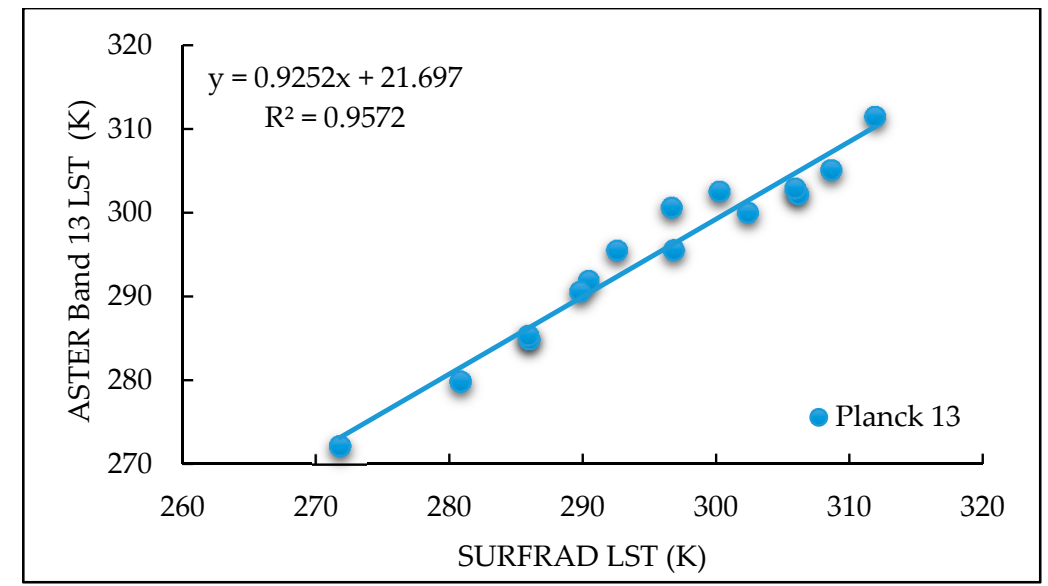

(a)

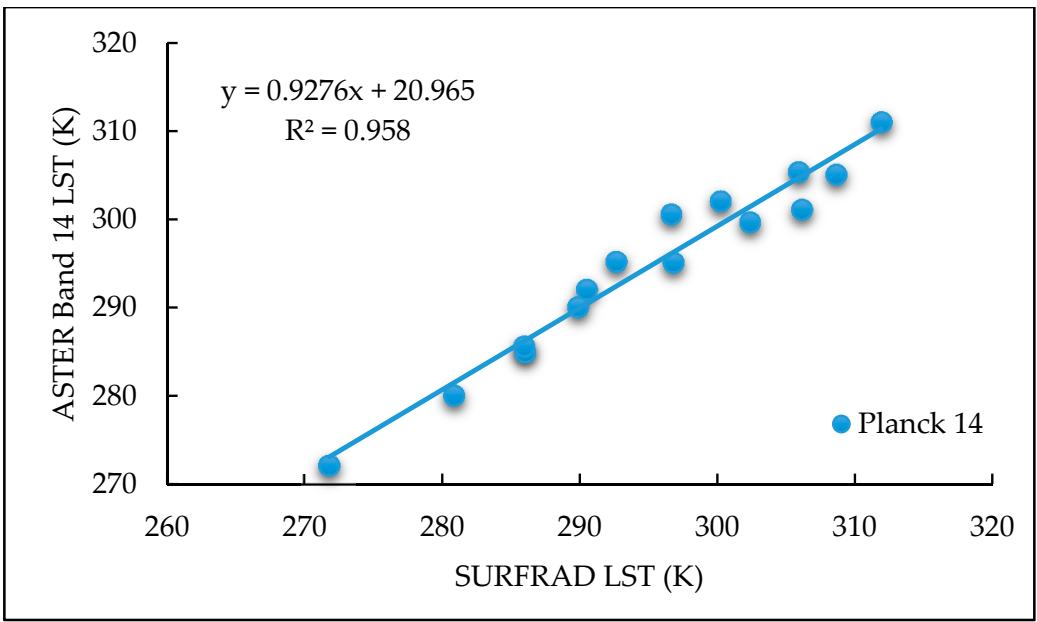

(b)

Figure 2. Comparison of scatter plots of LST inverted from ASTER data and LST derived from SURFRAD station at four SURFRAD stations: (a) scatter plot for LST values derived from ASTER band 13 using the Planck function and the LSTs derived from SURFRAD measurements; and (b) scatter plot for LST values derived from ASTER band 14 using the Planck function and the LSTs derived from SURFRAD measurements.

\subsection{Results from the Single Channel Algorithm (SCA)}

The SCA has been used in this study to derive the LST values from the VNIR and TIR imagery obtained from the ASTER sensor. The inverted LST values were thereafter compared to the actual land surface temperatures derived from the SURFRAD data. Tables 11 and 12 show the comparisons between the different LSTs derived from band 13 and band 14 of the ASTER instrument and the LSTs obtained from SURFRAD stations. All temperatures are measured in Kelvin. 
Table 11. Comparison of LST values derived from the SURFRAD stations and the LST inverted by the SCA using band 13 of the ASTER instrument.

\begin{tabular}{|c|c|c|c|c|c|c|c|c|c|c|c|}
\hline \multicolumn{3}{|c|}{ Bondville } & \multicolumn{3}{|c|}{ Fort Peck } & \multicolumn{3}{|c|}{ Goodwin Creek } & \multicolumn{3}{|c|}{ Sioux Falls } \\
\hline Date & LST (K) & Bias (K) & Date & LST (K) & Bias (K) & Date & LST (K) & Bias (K) & Date & LST (K) & Bias (K) \\
\hline 6 March 2002 & 285.92 & -0.12 & 11 June 2001 & 301.75 & -0.64 & 11 March 2004 & 297.08 & 0.23 & 9 January 2007 & 272.43 & 0.63 \\
\hline 7 November 2001 & 297.19 & 4.58 & 18 April 2008 & 304.30 & 4.04 & 14 June 2006 & 309.12 & 0.49 & 11 October 2006 & 286.35 & 0.38 \\
\hline 1 August 2006 & 309.15 & 3.01 & 30 August 2001 & 313.88 & 1.98 & 27 February 2002 & 280.56 & -0.29 & & & \\
\hline 10 October 2010 & 293.24 & 2.76 & & & & 10 October 2000 & 305.23 & -0.69 & & & \\
\hline 19 September 2004 & 302.99 & 6.31 & & & & & & & & & \\
\hline 30 October 2004 & 291.92 & 2.07 & & & & & & & & & \\
\hline$\Delta$ & & 3.10 & & & 1.79 & & & -0.06 & & & 0.51 \\
\hline$\sigma$ & & 1.68 & & & 1.57 & & & 0.30 & & & 0.36 \\
\hline RMSE & & 3.69 & & & 2.62 & & & 0.46 & & & 0.52 \\
\hline
\end{tabular}

$\Delta:$ Bias, $\sigma:$ Standard Deviation, RMSE: Root Mean Square Error.

Table 12. Comparison of LST values derived from the SURFRAD stations and the LST inverted by the SCA using band 14 of the ASTER instrument.

\begin{tabular}{|c|c|c|c|c|c|c|c|c|c|c|c|}
\hline \multicolumn{3}{|c|}{ Bondville } & \multicolumn{3}{|c|}{ Fort Peck } & \multicolumn{3}{|c|}{ Goodwin Creek } & \multicolumn{3}{|c|}{ Sioux Falls } \\
\hline Date & LST (K) & Bias (K) & Date & LST (K) & Bias (K) & Date & LST (K) & Bias (K) & Date & LST (K) & Bias (K) \\
\hline 6 March 2002 & 289.15 & 3.12 & 11 June 2001 & 304.35 & 1.97 & 11 March 2004 & 299.64 & 2.79 & 9 January 2007 & 275.68 & 0.31 \\
\hline 7 November 2001 & 299.80 & 7.19 & 18 April 2008 & 306.68 & 6.43 & 14 June 2006 & 311.75 & 3.13 & 11 October 2006 & 289.71 & -0.35 \\
\hline 1 August 2006 & 312.32 & 6.17 & 30 August 2001 & 316.11 & 4.21 & 27 February 2002 & 283.84 & 3.00 & & & \\
\hline 10 October 2010 & 296.37 & 5.89 & & & & 10 October 2000 & 307.72 & 1.80 & & & \\
\hline 19 September 2004 & 305.84 & 9.16 & & & & & & & & & \\
\hline 30 October 2004 & 294.43 & 4.59 & & & & & & & & & \\
\hline$\Delta$ & & 6.02 & & & 4.20 & & & 2.68 & & & 3.81 \\
\hline$\sigma$ & & 2.22 & & & 2.97 & & & 1.89 & & & 2.70 \\
\hline RMSE & & 6.31 & & & 4.58 & & & 2.73 & & & 3.81 \\
\hline
\end{tabular}


The LST values obtained from the SCA band 13 and band 14 produced positive bias values in comparison to LSTs derived from the SURFRAD measurements. The bias values of the values derived from ASTER band 13 and 14 were $1.65 \mathrm{~K}$ and $4.47 \mathrm{~K}$, respectively, for all scenes used in the study. According to the regression analysis, which was performed to determine the relationship between the LST values obtained from the SCA and the LST obtained from the SURFRAD data, a high correlation was obtained between the values: a correlation coefficient of 0.9676 was observed using the SCA and ASTER band 13 and a correlation coefficient of 0.9666 was observed using the SCA and ASTER band 14 . The SCA produced LST values with standard deviations of $1.11 \mathrm{~K}$ and $2.35 \mathrm{~K}$ for ASTER band 13 and band 14, respectively. Figure 3 shows the scatter plots produced to show the relationship between the LSTs derived from ASTER band 13 and 14 from the SCA with SURFRAD data. The SCA produced the best results when band 13 was used.

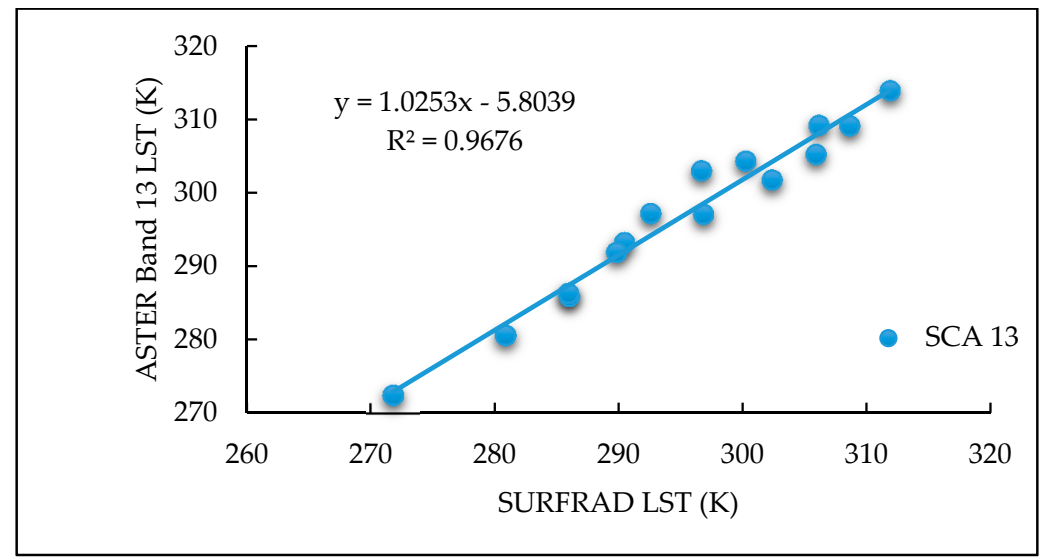

(a)

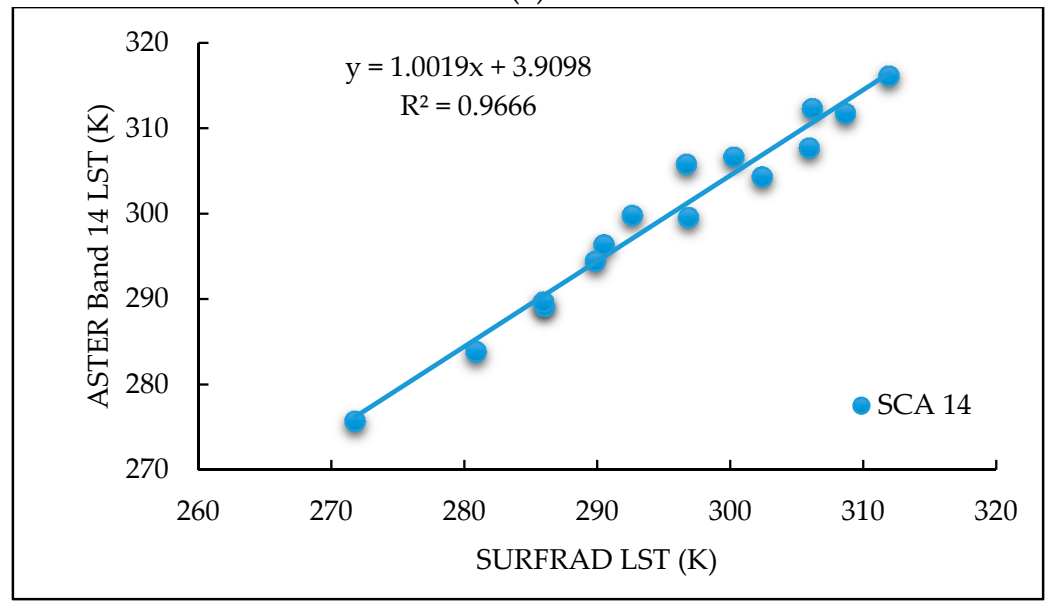

(b)

Figure 3. Comparison of scatter plots of LST inverted from ASTER data and LST derived from SURFRAD station at four SURFRAD stations: (a) scatter plot for LST values derived from ASTER band 13 using the SCA and the LSTs derived from SURFRAD measurements; and (b) scatter plot for LST values derived from ASTER band 14 using the SCA and the LSTs derived from SURFRAD measurements.

\subsection{Results from the Split Window Algorithm (SWA)}

This study has involved the SWA to derive LST from ASTER band 13 and band 14. The accuracy of the LSTs derived from the sensor though the use of the algorithm. The derived values were thereafter compared to the actual land surface temperatures derived from the SURFRAD data. Table 13 shows the comparison between the different LSTs derived from band 13 and band 14 of the ASTER instrument and the LSTs obtained from SURFRAD stations. All temperatures are measured in Kelvin. 
Table 13. Comparison of LST values derived from the SURFRAD stations and the LST inverted by the SWA using band 13 and band 14 of the ASTER instrument.

\begin{tabular}{|c|c|c|c|c|c|c|c|c|c|c|c|}
\hline \multicolumn{3}{|c|}{ Bondville } & \multicolumn{3}{|c|}{ Fort Peck } & \multicolumn{3}{|c|}{ Goodwin Creek } & \multicolumn{3}{|c|}{ Sioux Falls } \\
\hline Date & LST (K) & Bias (K) & Date & LST (K) & Bias (K) & Date & LST (K) & Bias (K) & Date & LST (K) & Bias (K) \\
\hline 6 March 2002 & 285.47 & -0.57 & 11 June 2001 & 299.33 & -3.06 & 11 March 2004 & 294.11 & -2.74 & 9 January 2007 & 271.59 & -0.21 \\
\hline 7 November 2001 & 294.24 & 1.63 & 18 April 2008 & 301.66 & 1.40 & 14 June 2006 & 308.95 & 0.33 & 11 October 2006 & 285.57 & -0.40 \\
\hline 1 August 2006 & 306.78 & 0.64 & 30 August 2001 & 309.98 & -1.92 & 27 February 2002 & 279.89 & -0.96 & & & \\
\hline 10 October 2010 & 292.56 & 2.07 & & & & 10 October 2000 & 302.21 & -3.71 & & & \\
\hline 19 September 2004 & 305.28 & 8.59 & & & & & & & & & \\
\hline 30 October 2004 & 287.53 & -2.32 & & & & & & & & & \\
\hline$\Delta$ & & 1.67 & & & -1.19 & & & -1.77 & & & -0.30 \\
\hline$\sigma$ & & 4.26 & & & 1.50 & & & 1.37 & & & 0.21 \\
\hline RMSE & & 3.80 & & & 2.23 & & & 2.36 & & & 0.32 \\
\hline
\end{tabular}

$\Delta$ : Bias, $\sigma:$ Standard Deviation, RMSE: Root Mean Square Error. 
In this study, the LST values obtained from the SWA produced a negative bias value in comparison to the LSTs derived from SURFRAD data. The algorithm produced a bias value of $-0.08 \mathrm{~K}$ and a standard deviation of $2.40 \mathrm{~K}$. It produced a regression coefficient of 0.9314 in relation to the data obtained from the SURFRAD stations. Figure 4 shows the scatter plots of the LSTs derived from ASTER using the SWA, ASTER band 13 and ASTER band 14 in relation to SURFRAD data.

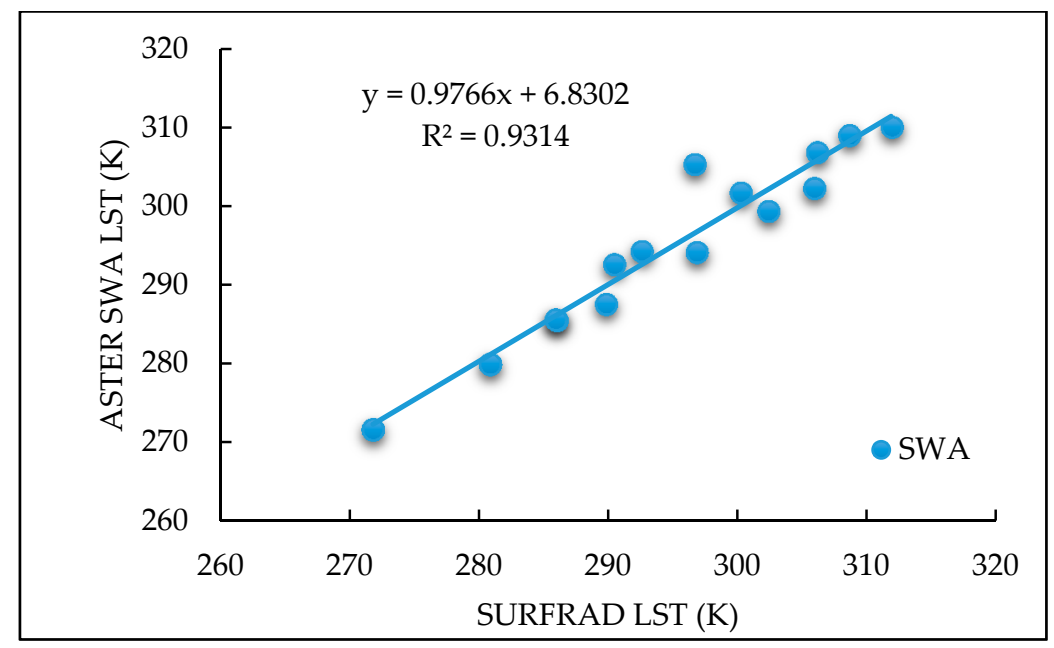

Figure 4. Comparison of scatter plots of LST inverted from ASTER data using the SWA and LST derived from SURFRAD station at four SURFRAD stations.

\subsection{Comparison of the Three Algorithms}

Unlike the Planck function, which does not require atmospheric parameters when inverting LST from the ASTER instrument's VNIR and TIR bands, the SWA and the SCA algorithms are heavily reliant on the atmospheric parameters of water vapor and transmittance. The accuracy of the SWA is high, but the algorithm is mostly limited due to the need to have prior knowledge of the atmospheric transmittance. According to tests which were done by Jimenez-Munoz and Sobrino, SWA have the ability to provide results with similar accuracies as the Thermal Emission Separation (TES) algorithm [50]. The main advantage of SWA algorithms is the ability to include atmospheric correction within the algorithms themselves.

This study has revealed that the SCA has an ability to produce the best results when ASTER band 13 is used. This has been observed in this study as band 13 produced the lowest values of standard deviation, Root Mean Square Error (RMSE) and bias in comparison to the SURFRAD measurements. The SCA band 14 produced the largest bias at the Fort Feck SURFRAD station where band 14 produced LST values with a RMSE of $4.58 \mathrm{~K}$.

The Planck function produced results with an average bias of $2.29 \mathrm{~K}$ when ASTER band 13 and band 14 were applied in all the scenes involved in the study while the SCA produced results with an average RMSE of $3.77 \mathrm{~K}$ using band 13 and band 14 for all scenes used in the study. The SWA produced results with a RMSE of $2.88 \mathrm{~K}$ with the use of band 13 and band 14 in all the scenes involved in the study.

\section{Conclusions}

In this study, three LST inversion algorithms from data obtained from the ASTER instrument were compared. To enable more users to make use of the algorithms, the Python script used in the Geoprocessing of the algorithms has been shared as a plugin for a free and open source software known as Quantum GIS (QGIS). The script is provided as an update to a script written in a previous study [13]. 
From the scenes used in the study, the results show that the Planck function can produce the best results in comparison to the other algorithms, while the SWA algorithm has a moderate accuracy and the SCA algorithm has the lowest accuracy. All algorithms used in the study have shown an ability to produce land surface temperature values with an accuracy of up to $4 \mathrm{~K}$. It is expected that through this study more users of ASTER data from different areas of specialization such as hydrology, energy studies and climate related sciences will manage to derive LST from ASTER imagery in an easy and automated way.

Acknowledgments: This study was supported by Anadolu University Scientific Research Projects Commission under the grant number 1601F031. We sincerely appreciate the research funding which was provided by Anadolu University for this article. The authors would like to express their high gratitude to the ASTER science team and the National Oceanic and Atmospheric Administration (NOAA) for providing SURFRAD ground data free of charge. Special thanks go to the United States Geological Survey (USGS) for providing the image archives. Finally, the authors would like to thank the QGIS development team for creating an API which allows users to make use of the QGIS software for Python Geoprocessing.

Author Contributions: In this manuscript, Milton Isaya Ndossi wrote the Python Geoprocessing script used in the data analysis and wrote the manuscript; and Ugur Avdan evaluated the study and contributed in the methodology and revisions.

Conflicts of Interest: The authors declare no conflict of interest.

\section{Abbreviations}

The following abbreviations are used in this manuscript:

$\begin{array}{ll}\text { ASTER } & \text { Advanced Space-borne Thermal Emission and Reflection Radiometer } \\ \text { K } & \text { Kelvin } \\ \text { LSE } & \text { Land Surface Emissivity } \\ \text { MODTRAN } & \text { MODerate resolution atmospheric TRANsmission } \\ \text { MODIS } & \text { Moderate-Resolution Imaging Spectroradiometer } \\ \text { NASA } & \text { National Aeronautics and Space Administration } \\ \text { NOAA } & \text { National Oceanic and Atmospheric Administration } \\ \text { NDVI } & \text { Normalized Difference Vegetation Index } \\ \text { NIR } & \text { Near Infrared } \\ \text { SCA } & \text { Single Channel Algorithm } \\ \text { SURFRAD } & \text { Surface Radiation budget network } \\ \text { SWA } & \text { Split Window Algorithm } \\ \text { TIR } & \text { Thermal Infrared } \\ \text { UCC } & \text { Unit Conversion Coefficients } \\ \text { USGS } & \text { United States Geological Survey } \\ \text { VNIR } & \text { Visible and Near Infrared }\end{array}$

\section{References}

1. Gillespie, A.; Rokugawa, S.; Matsunaga, T.; Cothern, J.S.; Hook, S.; Kahle, A.B. A temperature and emissivity separation algorithm for advanced spaceborne thermal emission and reflection radiometer (ASTER) images. IEEE Trans. Geosci. Remote Sens. 1998, 36, 1113-1126. [CrossRef]

2. Dousset, B.; Gourmelon, F. Satellite multi-sensor data analysis of urban surface temperatures and landcover. ISPRS J. Photogramm. Remote Sens. 2003, 58, 43-54. [CrossRef]

3. Weng, Q.; Lu, D.; Schubring, J. Estimation of land surface temperature-vegetation abundance relationship for urban heat island studies. Remote Sens. Environ. 2004, 89, 467-483. [CrossRef]

4. Prata, A.; Caselles, V.; Coll, C.; Sobrino, J.; Ottle, C. Thermal remote sensing of land surface temperature from satellites: Current status and future prospects. Remote Sens. Rev. 1995, 12, 175-224. [CrossRef]

5. Li, Z.-L.; Tang, B.-H.; Wu, H.; Ren, H.; Yan, G.; Wan, Z.; Trigo, I.F.; Sobrino, J.A. Satellite-derived land surface temperature: Current status and perspectives. Remote Sens. Environ. 2013, 131, 14-37. [CrossRef]

6. Buis, A. Nasa, Japan Make ASTER Earth Data available at No Cost. Available online: http:/ /www.nasa. gov/feature/jpl/nasa-japan-make-aster-earth-data-available-at-no-cost (accessed on 29 April 2016).

7. Jiménez-Muñoz, J.C.; Sobrino, J.A. A single-channel algorithm for land-surface temperature retrieval from ASTER data. IEEE Geosci. Remote Sens. Lett. 2010, 7, 176-179. [CrossRef] 
8. Mao, K.; Tang, H.; Chen, Z.; Qiu, Y.; Qin, Z.; Li, M. A split-window algorithm for retrieving land-surface temperature from ASTER data. Remote Sens. Inf. 2006, 5, 7-11.

9. Jiménez-Muñoz, J.C.; Sobrino, J.A.; Gillespie, A.; Sabol, D.; Gustafson, W.T. Improved land surface emissivities over agricultural areas using ASTER NDVI. Remote Sens. Environ. 2006, 103, 474-487. [CrossRef]

10. Qin, Z.; Dall'Olmo, G.; Karnieli, A.; Berliner, P. Derivation of split window algorithm and its sensitivity analysis for retrieving land surface temperature from NOAA-advanced very high resolution radiometer data. J. Geophys. Res. Atmos. 2001, 106, 22655-22670. [CrossRef]

11. Artis, D.A.; Carnahan, W.H. Survey of emissivity variability in thermography of urban areas. Remote Sens. Environ. 1982, 12, 313-329. [CrossRef]

12. Team, Q.D. QGIS Python Plugins Repository. Available online: http://plugins.qgis.org/plugins/ (accessed on 11 May 2016).

13. Isaya Ndossi, M.; Avdan, U. Application of open source coding technologies in the production of land surface temperature (LST) maps from Landsat: A PYQGIS plugin. Remote Sens. 2016, 8, 413. [CrossRef]

14. Augustine, J.A.; DeLuisi, J.J.; Long, C.N. SURFRAD-A national surface radiation budget network for atmospheric research. Bull. Am. Meteorol. Soc. 2000, 81, 2341-2357. [CrossRef]

15. United States Geological Survey. Earth Explorer. Available online: http://earthexplorer.usgs.gov/ (accessed on 5 May 2016).

16. Yu, X.; Guo, X.; Wu, Z. Land surface temperature retrieval from Landsat 8 TIRS—Comparison between radiative transfer equation-based method, split window algorithm and single channel method. Remote Sens. 2014, 6, 9829-9852. [CrossRef]

17. Heidinger, A.K.; Laszlo, I.; Molling, C.C.; Tarpley, D. Using SURFRAD to verify the NOAA single-channel land surface temperature algorithm. J. Atmos. Ocean. Technol. 2013, 30, 2868-2884. [CrossRef]

18. Wang, K.; Liang, S. Evaluation of ASTER and MODIS land surface temperature and emissivity products using long-term surface longwave radiation observations at SURFRAD sites. Remote Sens. Environ. 2009, 113, 1556-1565. [CrossRef]

19. United States Department Commerce/National Oceanic and Atmospheric Administration. Surfrad Site Information. Available online: http://www.esrl.noaa.gov/gmd/grad/surfrad/sitepage.html (accessed on 28 October 2016).

20. Gebreslasie, M.; Ahmed, F.; van Aardt, J.A. Image-based reflectance conversion of ASTER and IKONOS imagery as precursor to structural assessment of plantation forests in KwaZulu-Natal, South Africa. South. For. 2009, 71, 259-265. [CrossRef]

21. Abrams, M.; Hook, S.; Ramachandran, B. ASTER User Handbook, version 2; Jet Propulsion Laboratory: Pasadena, CA, USA, 2002.

22. Society, A.M. Brightness Temperature. Available online: http://glossary.ametsoc.org/wiki/Brightness_ temperature (accessed on 27 October 2016).

23. Boori, M.S. A comparison of land surface temperature, derived from AMSR-2, Landsat and ASTER satellite data. J. Geogr. Geol. 2015, 7, 61-69. [CrossRef]

24. Society, A.M. Emissivity. Available online: http://glossary.ametsoc.org/wiki/Emissivity (accessed on 27 October 2016).

25. Prabhakara, C.; Dalu, G. Remote sensing of the surface emissivity at $9 \mu$ m over the globe. J. Geophys. Res. 1976, 81, 3719-3724. [CrossRef]

26. Mallick, J.; Singh, C.K.; Shashtri, S.; Rahman, A.; Mukherjee, S. Land surface emissivity retrieval based on moisture index from Landsat TM satellite data over heterogeneous surfaces of Delhi city. Int. J. Appl. Earth Obs. Geoinf. 2012, 19, 348-358. [CrossRef]

27. Salisbury, J.W.; D'Aria, D.M. Emissivity of terrestrial materials in the $8-14 \mu \mathrm{m}$ atmospheric window. Remote Sens. Environ. 1992, 42, 83-106. [CrossRef]

28. Peres, L.F.; DaCamara, C.C. Land surface temperature and emissivity estimation based on the two-temperature method: Sensitivity analysis using simulated MSG/SEVIRI data. Remote Sens. Environ. 2004, 91, 377-389. [CrossRef]

29. Snyder, W.C.; Wan, Z.; Zhang, Y.; Feng, Y.-Z. Classification-based emissivity for land surface temperature measurement from space. Int. J. Remote Sens. 1998, 19, 2753-2774. [CrossRef]

30. Sun, D.; Pinker, R. Retrieval of surface temperature from the MSG-SEVIRI observations: Part I. Methodology. Int. J. Remote Sens. 2007, 28, 5255-5272. [CrossRef] 
31. Becker, F.; Li, Z.-L. Temperature-independent spectral indices in thermal infrared bands. Remote Sens. Environ. 1990, 32, 17-33. [CrossRef]

32. Sobrino, J.A.; Jiménez-Muñoz, J.C.; Sòria, G.; Romaguera, M.; Guanter, L.; Moreno, J.; Plaza, A.; Martínez, P. Land surface emissivity retrieval from different VNIR and TIR sensors. IEEE Trans. Geosci. Remote Sens. 2008, 46, 316-327. [CrossRef]

33. Sobrino, J.; Raissouni, N.; Li, Z.-L. A comparative study of land surface emissivity retrieval from NOAA data. Remote Sens. Environ. 2001, 75, 256-266. [CrossRef]

34. Valor, E.; Caselles, V. Mapping land surface emissivity from NDVI: Application to European, African, and South American areas. Remote Sens. Environ. 1996, 57, 167-184. [CrossRef]

35. Sobrino, J.A.; Jiménez-Muñoz, J.C.; Paolini, L. Land surface temperature retrieval from LANDSAT TM 5. Remote Sens. Environ. 2004, 90, 434-440. [CrossRef]

36. Momeni, M.; Saradjian, M. Evaluating NDVI-based emissivities of MODIS bands 31 and 32 using emissivities derived by Day/Night LST algorithm. Remote Sens. Environ. 2007, 106, 190-198. [CrossRef]

37. Sobrino, J.; Raissouni, N. Toward remote sensing methods for land cover dynamic monitoring: Application to morocco. Int. J. Remote Sens. 2000, 21, 353-366. [CrossRef]

38. Peres, L.F.; DaCamara, C.C. Emissivity maps to retrieve land-surface temperature from MSG/SEVIRI. IEEE Trans. Geosci. Remote Sens. 2005, 43, 1834-1844. [CrossRef]

39. Sobrino, J.; El Kharraz, J.; Li, Z.-L. Surface temperature and water vapour retrieval from MODIS data. Int. J. Remote Sens. 2003, 24, 5161-5182. [CrossRef]

40. Van de Griend, A.; Owe, M. On the relationship between thermal emissivity and the normalized difference vegetation index for natural surfaces. Int. J. Remote Sens. 1993, 14, 1119-1131. [CrossRef]

41. Carlson, T.N.; Ripley, D.A. On the relation between NDVI, fractional vegetation cover, and leaf area index. Remote Sens. Environ. 1997, 62, 241-252. [CrossRef]

42. Jiménez-Muñoz, J.C.; Sobrino, J.A. A generalized single-channel method for retrieving land surface temperature from remote sensing data. J. Geophys. Res. Atmos. 2003, 108. [CrossRef]

43. Jiménez-Muñoz, J.C.; Cristóbal, J.; Sobrino, J.A.; Soria, G.; Ninyerola, M.; Pons, X. Revision of the single-channel algorithm for land surface temperature retrieval from Landsat thermal-infrared data. IEEE Trans. Geosci. Remote Sens. 2009, 47, 339-349. [CrossRef]

44. Becker, F.; Li, Z.-L. Towards a local split window method over land surfaces. Remote Sens. 1990, 11, 369-393. [CrossRef]

45. Caselles, V.; Coll, C.; Valor, E. Land surface emissivity and temperature determination in the whole HAPEX-Sahel area from AVHRR data. Int. J. Remote Sens. 1997, 18, 1009-1027. [CrossRef]

46. Price, J.C. Land surface temperature measurements from the split window channels of the NOAA 7 advanced very high resolution radiometer. Geophys. Res. Atmos. 1984, 89, 7231-7237. [CrossRef]

47. Wang, S.; He, L. Practical split-window algorithm for retrieving land surface temperature over agricultural areas from ASTER data. J. Appl. Remote Sens. 2014, 8, 083582. [CrossRef]

48. Stathopoulou, M.; Cartalis, C. Daytime urban heat islands from Landsat ETM+ and Corine land cover data: An application to major cities in Greece. Sol. Energy 2007, 81, 358-368. [CrossRef]

49. Liu, L.; Zhang, Y. Urban heat island analysis using the Landsat TM data and ASTER data: A case study in Hong Kong. Remote Sens. 2011, 3, 1535-1552. [CrossRef]

50. Jiménez-Muñoz, J.C.; Sobrino, J.A. Feasibility of retrieving land-surface temperature from ASTER TIR bands using two-channel algorithms: A case study of agricultural areas. IEEE Geosci. Remote Sens. Lett. 2007, 4, 60-64. [CrossRef]

(C) 2016 by the authors; licensee MDPI, Basel, Switzerland. This article is an open access article distributed under the terms and conditions of the Creative Commons Attribution (CC-BY) license (http://creativecommons.org/licenses/by/4.0/). 